\title{
CORRECTION
}

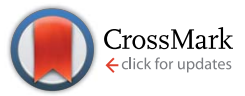

Cite this: J. Mater. Chem. A, 2016, 4 , 8913

DOI: $10.1039 / c 6 t a 90102 f$

www.rsc.org/MaterialsA

\section{Correction: $\mathrm{BaTiO}_{3}-\mathrm{BiYbO}_{3}$ perovskite materials for energy storage applications}

\author{
Zhengbo Shen, Xiaohui Wang, ${ }^{*}$ Bingcheng Luo and Longtu Li \\ Correction for ' $\mathrm{BaTiO}_{3}-\mathrm{BiYbO}_{3}$ perovskite materials for energy storage applications' by Zhengbo Shen et al., \\ J. Mater. Chem. A, 2015, 3, 18146-18153.
}

The authors of this article were not aware at the time of its publication that similar materials to those reported had previously been reported by Strathdee $e t a l$. in 2011. ${ }^{1}$ The authors would therefore like to cite the work of Strathdee $e t$ al. and apologise for this oversight. However, Strathdee et al. mainly focused on the ferroelectric-to-relaxor crossover in $(1-x) \mathrm{BaTiO}_{3}-x \mathrm{BiYbO}_{3}(0 \leq x \leq$ 0.08). While the authors not only studied the phase structures, phase transition, dielectric properties and relaxation behavior, they also studied the energy storage properties of $(1-x) \mathrm{BaTiO}_{3}-x \mathrm{BiYbO}_{3}(x=0.00-0.20)$. The authors demonstrated a more systematic study and further explored the application of the materials in energy storage applications.

The Royal Society of Chemistry apologises for these errors and any consequent inconvenience to authors and readers.

\section{Reference}

1 T. Strathdee, L. Luisman, A. Feteira and K. Reichmann, J. Am. Ceram. Soc., 2011, 94, 2292-2295. 